\title{
Hippocampal Remodeling and Damage by Corticosteroids: Implications for Mood Disorders
}

\author{
E. Sherwood Brown, M.D., Ph.D., A. John Rush, M.D., and Bruce S. McEwen, Ph.D.
}

Mood disorders are common, recurrent and disabling illnesses which are frequently associated with hypothalamic-pituitary-adrenal (HPA) axis dysregulation and memory loss. The hippocampus provides negative feedback to the HPA axis and has an important role in key aspects of spatial and declarative memory. Thus, hippocampal dysfunction could account for both the memory impairment and neuroendocrine abnormalities found in mood disorders. The critical role of the hippocampus in declarative memory, emotional processing, and vulnerability to stress has been demonstrated in both animal and human studies. Cellular processes in the hippocampus including long-term potentiation, neurogenesis, and dendritic remodeling are currently areas of intense study. Human studies report cognitive impairment consistent with hippocampal dysfunction in depression, bipolar disorder, Cushing's disease, and in those individuals receiving exogenous corticosteroids. This review examines data on the role of corticosteroids in hippocampal remodeling and atrophy in patients with mood disorders. Interventions to prevent or reverse the damaging effects of corticosteroids on the hippocampus are discussed.

[Neuropsychopharmacology 21:474-484, 1999]

(C) 1999 American College of Neuropsychopharmacology.

Published by Elsevier Science Inc.
KEY WORDS: Hippocampus; Corticosteroid; Cortisol; Depression; Bipolar disorder; Memory

The role of the hippocampus in memory has long been appreciated. Over forty years ago, severe amnesia in a patient following removal of this brain region for seizure control was reported (Scoville and Milner 1957). More recent reports have suggested that a functional hippocampus is needed for a specific cognition process

From the Department of Psychiatry, The University of Texas Southwestern Medical Center, Dallas, TX (ESB, AJR); and the Harold and Margaret Milliken Hatch Laboratory of Neuroendocrinology, Rockefeller University, New York, NY (BSMc).

Address correspondence to: E. Sherwood Brown, Ph.D., M.D. Assistant Professor, Department of Psychiatry, UT Southwestern Medical Center, St. Paul Professional Bldg. I, Suite 600, 5959 Harry Hines Blvd., Dallas, Texas 75235-9101.

Received January 13, 1999; revised March 31, 1999; accepted April 20, 1999 . termed declarative, explicit, or relational memory which requires conscious reflection in contrast to reflexive memory which is not dependent on conscious awareness (Eichenbaum et al. 1992; Squire 1992; Kandel and Schwartz 1985). Surgical removal of the temporal lobe, including the hippocampus, is associated with deficits in declarative memory in humans (Baxendale et al. 1998), and hippocampal volume is correlated with declarative memory performance (Golomb et al. 1994).

Mood disorders are frequently associated with hypercortisolemia, and an associated finding is impaired information processing and memory loss. The hippocampus provides negative feedback to the hypothalamic-pituitary-adrenal axis (HPA). In a recent review, the suggestion was made that changes in the hippocampus, secondary to stress, may be central to the development of depression in vulnerable individuals (Duman et al. 1997). One possible mechanism of injury to the hippocampus is corticosteroid exposure. Animal data 
reveal that an excess of corticosteroids causes both reversible and irreversible changes in hippocampal structure and cognition, a topic which has been previously reviewed (Lupien and McEwen 1997; McEwen 1997, 1999; Sapolsky 1992). Thus, an excess of corticosteroids and resulting hippocampal damage could contribute both to further cortisol elevations through impaired negative feedback to the HPA axis, and cognitive impairment in depressed persons.

This article reviews the evidence that the cumulative effects of hippocampal damage by corticosteroids lead to neuroendocrine abnormalities, cognitive impairment and increased vulnerability to future episodes of affective illness. Evidence supporting the hypothesis that hypercortisolemia leads to hippocampal dysfunction in humans with mood disorders will be discussed. Specifically, four predictions arising from this hypothesis are explored: 1) frequency of dexamethasone suppression test (DST) non-suppression should greaten with increasing number of affective episodes or more total time with mood symptoms; 2) cognitive functions mediated by the hippocampus should become more impaired as number of episodes or length of illness increases; 3) there should be a negative correlation between episode number or illness length and hippocampal volume; and 4) hypercortisolemic mood disorder patients should have more cognitive impairment and smaller hippocampal volumes than normocortisolemic patients.

Pertinent findings from patients with Cushing's disease and patients receiving exogenous corticosteroids are also discussed as these populations provide additional support for memory loss and structural changes in the hippocampus in humans secondary to corticosteroids. Potential interventions to protect the hippocampus are also examined.

\section{HPA AXIS REGULATION BY THE HIPPOCAMPUS}

The hippocampus is a primary CNS target for corticosteroids (McEwen et al. 1968, De Kloet et al. 1998). Thus, injury to the hippocampus by corticosteroids could lead to elevated levels of corticotropin releasing hormone $(\mathrm{CRH})$, adrenocorticotropin (ACTH), and cortisol (Figure 1). However, hippocampal interactions with the HPA axis are complex and may be mediated, at least in part, by the paraventricular nucleus (PVN) and the bed nucleus of the stria terminalis (BNST) (see Herman and Cullinan 1997 for a review).

Considerable evidence in animals demonstrates the importance of the hippocampus in HPA axis modulation (Jacobson and Sapolsky 1991). Hippocampal le-

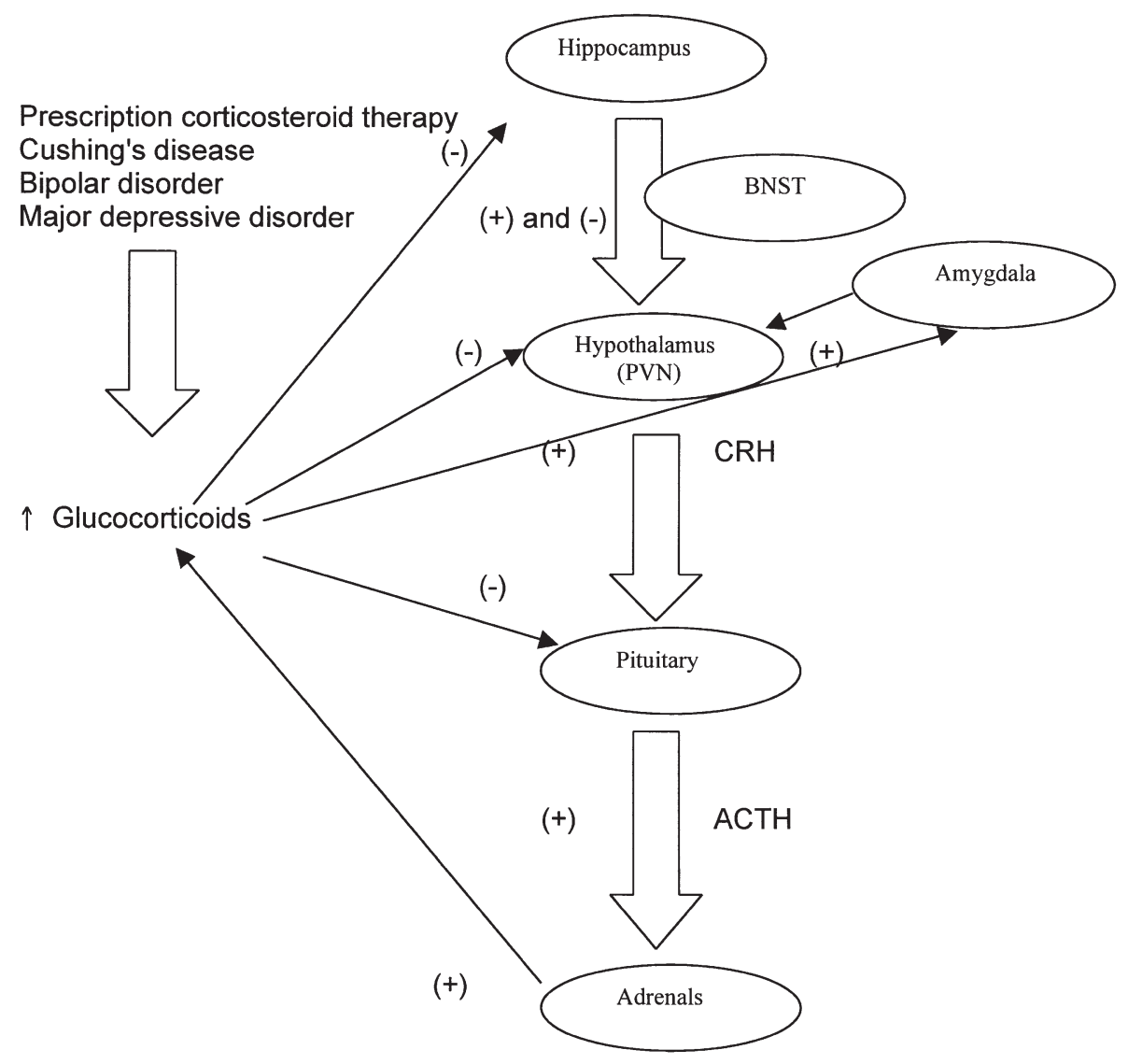

Figure 1. The hippocampus has complex interactions with the HPA axis including both positive and inhibitory effects. These effects involve polysynaptic pathways in which the bed nucleus of the stria terminalis (BNST) is involved and which converge on the paraventricular nuclei (PVN) along with influences from other brain regions such as the amygdala (Herman and Cullinan 1997). Elevated levels of corticosteroids provide a negative feedback to the HPA axis by operating on a number of different brain structures as well as the anterior pituitary. Note that glucocorticoids may have a positive feedback effect on HPA activation via the amygdala CRH system (Shulkin et al. 1998). 
sions are associated with hypersecretion of glucocorticoids during stress-induced activation of the HPA axis (Feldman and Weidenfeld 1991; Feldman and Conforti 1976; Slusher 1966; Wilson et al. 1980; Fischette et al. 1980; Kim and Kim 1961; Knigge and Hays 1963; Moberg et al. 1971; Feldman and Conforti 1980), whereas stimulation of the hippocampus inhibits the adrenocortical stress response (Bouille and Bayle 1973; Rubin et al. 1966; Mandell et al. 1962; Slusher and Hyde 1961). Stimulation of the CA3 region dentate and subiculum appears to increase corticosteroid levels while CA1 stimulation decreases corticosterone levels in rats (Dunn and Orr 1984), suggesting both positive and inhibitory effects of different hippocampal regions on the HPA axis.

HPA axis inhibition by the hippocampus appears to be mediated by negative feedback from circulating glucocorticoids. Destruction of the dorsal hippocampus attenuates the ability of dexamethasone to suppress the stress response (Feldman and Conforti 1980). Loss of the normal glucocorticoid fast feedback, mediated, in part, by the hippocampus, has been reported in humans with depression and animals in chronic stress paradigms (Sapolsky et al. 1986a; Young et al. 1991; Liberzon et al. 1997).

Therefore, elevated levels of cortisol secondary to hippocampal damage could produce further injury to the hippocampus itself, and consequently, even greater increases in cortisol levels due to impaired feedback mechanisms to suppress cortisol release, a concept termed the "glucocorticoid cascade hypothesis" (Sapolsky et al. 1986b).

\section{EVIDENCE OF HYPERCORTISOLEMIA IN MOOD DISORDERS}

Both, an excess of cortisol and DST non-suppression, have been reported for many years in patients with mood disorders (Sachar 1971; Carroll 1981). An analysis of over 150 studies reported that $43 \%$ of persons with major depressive disorder (MDD) $(n=4411), 67 \%$ with psychotic depression $(n=150), 41 \%$ with mania $(n=$ $137)$, and $78 \%$ with mixed mania $(n=41)$ have DST non-suppression (Arana et al. 1985; Arana and Mossman 1988). Non-suppression may be age dependent increasing from only $34 \%$ in patients under 18 years old to $64 \%$ in patients greater than 60 years old. Other studies have reported a positive correlation between DST non-suppression and the number of depressive episodes (Yerevanian et al. 1984; Lenox et al. 1985). DST non-suppression often returns to normal as the mood symptoms resolve. However, persistent DST non-suppression is associated with a higher likelihood of relapse in MDD than if the DST normalizes (Greden et al. 1983; Targum 1984). Similar findings of increased relapse with persistent HPA axis dysregulation have recently been reported both in depressed and bipolar patients using the combined dexamethasone suppression/corticotropin releasing hormone (DEX/CRH) challenge test (Holsboer et al. 1987; Holsboer-Trachsler 1991; Holsboer-Trachsler et al. 1994; Schmider et al. 1995).

\section{EVIDENCE OF HIPPOCAMPAL IMPAIRMENT SECONDARY TO CORTICOSTEROIDS IN HUMANS}

In animal models, exposure to high levels of corticosteroids has detrimental effects on both associative learning and spatial memory (Bohus 1970; Bohus and Lissak 1968; Greidanus 1970). Administration of corticosteroids accelerates the extinction of a shock avoidance response, a measure of associative learning (Bohus 1970; Bohus and Lissak 1968; Greidanus 1970). Spatial memory, assessed using mazes, is impaired in a dose-dependent manner with corticosterone administration in rats (Vicedomini et al. 1986). However, corticosterone administration also restores defects in spatial memory secondary to adrenalectomy, suggesting biphasic effects of the hormones in animals (McCormick et al. 1997). As will be discussed, memory deficits in humans with mood disorders, Cushing's disease, and patients receiving exogenous corticosteroids, also suggest hippocampal dysfunction.

\section{Cognitive Function in Mood Disorders}

Significant impairment in declarative memory is reported in depressed in- (Weingartner et al. 1981; RoyByrne et al. 1986) and out-patients (Calev et al. 1986; Sabe 1995) compared to controls. Cognitive function appears to improve with resolution of mood symptoms (Sternberg and Jarvik 1976; Fromm and Schopflocher 1984; Bulbena and Berrios 1993; Henry et al. 1973; Richardson et al. 1994; Strömgren 1977). However, some degree of cognitive impairment has been reported even after recovery in some (Paradiso et al. 1997; Coello et al. 1990; Abas et al. 1990; Marcos et al. 1994; Trichard et al. 1995), but not all (Fromm and Schopflocher 1984) studies. Cognitive function has also been investigated in several studies of patients with bipolar disorder, again finding cognitive impairment even in euthymic patients in most (McKay et al. 1995; Coffman et al. 1990; Sapin et al. 1987; Morice 1990; Tham et al. 1997) but not all (Calev et al. 1986) investigations.

Two recent studies have investigated cognitive function in euthymic patients with multiple affective episodes. Specific deficits in verbal memory were reported in 25 euthymic bipolar patients (mean illness duration $=$ 22 years) compared to controls (van Gorp 1998). There was a significant negative correlation between lifetime months of affective illness and memory suggesting that cognitive performance worsens over multiple episodes. 
In another investigation, significant impairment in several cognitive tests compared to controls $(n=58)$ was reported both in euthymic bipolar $(n=28)$ and $\operatorname{MDD}(n=$ 118) patients (Kessing 1998). The degree of cognitive impairment was greater in patients with multiple episodes and correlated with the number of prior episodes.

Data from these two studies must be interpreted with some caution however, given that many, but not all, of the subjects were receiving psychiatric medication at the time of cognitive testing. Lithium therapy has been associated with cognitive impairment in some (Lund et al. 1982; Squire et al. 1980; Christodoulou et al. 1981; Reuss et al. 1979; Kocsis et al. 1993) but not other studies (Friedman et al. 1977; Telford and Worrall 1978; Marusarez et al. 1981; Anath et al. 1981; Engelsmann et al. 1992; Joffe et al. 1988). Although lithium and other medication effects may contribute to the cognitive impairment observed in these studies, only $20 \%$ of the subjects in the Kessing (1998) investigation were taking lithium at the time of testing. In the van Gorp et al. (1998) study, all subjects were taking lithium but no correlation was found between serum lithium levels and cognitive impairment.

Cognitive function in humans with mood disorders may be associated with elevated cortisol levels and DST non-suppression. Cognitive impairment in depressed patients was significantly related to mean urinary free cortisol levels in one study (Rubinow et al. 1984). Similarly, most (Winokur et al. 1987; Wolkowitz et al. 1990; Siegel et al. 1989; Wauthy et al. 1991) but not all (Georgotas et al. 1986; Caine et al. 1984) studies have found greater cognitive impairment in DST non-suppressors than suppressors, with the discrepancy possibly due to differences in DST methodology (Wauthy et al. 1991). An additional explanation for these differences may be that the studies have not used the same instruments for assessing cognitive function. One study, specifically, examined declarative memory and found significantly greater errors of commission in verbal learning tasks in depressed DST non-suppressors than suppressors or normal controls (Wolkowitz et al. 1990).

Thus, an abundance of data supports cognitive impairment during episodes of major affective illness, which appears to improve with symptom remission, though some studies have documented persistent cognitive dysfunction even in euthymic patients with MDD or bipolar disorder. Furthermore, the majority of investigations have found greater cognitive impairment in depressed subjects with HPA axis abnormalities.

\section{Cognitive Impairment with Exogenous Corticosteroids and Cushing's Disease}

Cognitive impairment is found both in Cushing's disease and during exogenous corticosteroid exposure providing additional support for the hypothesis that these hormones are associated with hippocampal dysfunction. Deficits were reported in several measures of cognitive performance in 25 patients with Cushing's disease, which improved with treatment of the hypercortisolemia (Mauri et al. 1993). In another study, impairment in declarative memory was negatively correlated with mean plasma cortisol levels in 12 patients with Cushing's disease (Starkman and Schteingart 1981).

Memory deficits have also been reported in patients receiving short (Naber et al. 1996; Bender et al. 1988; Oliveri et al. 1998) or long-term (Keenan et al. 1996) corticosteroid therapy. Deficits in declarative memory were observed in subjects receiving even 4-5 days of dexamethasone or prednisone (Wolkowitz et al. 1990; Newcomer et al. 1994). A similar, reversible and, dose-dependent impairment in declarative memory was reported with high dose (160 mg/day) but not low dose (40 mg/day) hydrocortisone administration, suggesting similar memory deficits with both cortisol and synthetic corticosteroids (Newcomer et al. 1997; personal communication). Thus, data suggest cognitive impairment including declarative memory in Cushing's syndrome and during exogenous administration similar to those reported in patients with mood disorders.

\section{Structural Brain Changes in Mood Disorders}

Several investigators have examined hippocampal volumes in subjects with mood disorders. No significant difference in the amygdala-hippocampal volume was found between depressed patients $(n=19)$ and normal controls $(n=30)$ in one investigation (Axelson et al. 1993). However, a significant negative correlation was found between post-dexamethasone cortisol concentration and amygdala-hippocampal volume suggesting that smaller hippocampi are associated with poor suppression of cortisol. In this study, the sensitivity to detect hippocampal atrophy may have been limited by the use of methods which did not separate amygdala from hippocampus.

A more recent investigation examined hippocampal volumes using MRI in 10 asymptomatic and normocortisolemic subjects with a history of recurrent MDD and 10 matched controls (Sheline et al. 1996). The depressed subjects had $11 \%(p=0.02)$ and $15 \%(p=.003)$ smaller right and left hippocampi, respectively, than controls. There was a significant correlation between the total lifetime days depressed $(r=-0.65, p=.04)$ and the left hippocampal volume as well as a trend toward a relationship on the right $(r=-0.59, p=.1)$. Significantly reduced grey matter density in the left temporal cortex, including the hippocampus on MRI in middle-aged patients with chronic treatment refractory MDD compared to normal controls has also been observed (Shah et al. 1998). A matched group of patients recovered 
from depression did not differ from controls. This finding, in contrast to the investigation by Sheline et al. (1996), where even asymptomatic patients had significant hippocampal atrophy, suggests a potentially reversible process. Thus, even hippocampal changes substantial enough to be detected using MRI may not imply permanent damage.

The hippocampus has also been explored using MRI in persons with bipolar disorder. Significantly smaller temporal lobe volumes $(p=.0093)$ in patients with bipolar disorder $(n=10)$ compared to normal controls $(n=$ 10) were reported (Altshuler et al. 1991). In men, but not women, a significant negative correlation was observed between the duration of illness and the right temporal lobe volume $(r=0.92, p=.028)$. However, a more recent investigation found no significant differences in either temporal lobe or hippocampal volumes in euthymic male bipolar subjects $(n=12)$ compared to normal controls $(n=18)$ (Altshuler et al. 1998). The earlier investigation used a scanner with lower resolution ( $0.5 \mathrm{vs.}$ 1.5 tesla) and included younger subjects (40 vs. 52 years), as well as inpatients and symptomatic subjects, whereas the more recent study used subjects asymptomatic for at least three months. Therefore, as smaller volumes were only observed in the sample containing symptomatic patients, the atrophy in this population could be due to a state dependent process. In addition, by excluding subjects without full interepisode recovery, the more recent study may have excluded patients with chronic mood symptoms, perhaps the group most likely to have hippocampal atrophy.

However, it is important to note hippocampal atrophy may be only one example of structural changes in the forebrain related to mood disorders. Atrophy of the amygdala in MDD (Sheline et al. 1998), and enlargement in bipolar disorder (Altshuler et al. 1998) have recently been reported. Decreased grey matter volume in the prefrontal cortex, reportedly secondary to glial reduction, have also been observed in patients with mood disorders (Drevets et al. 1997; Ongür et al. 1998). Thus, structural changes in brain regions other than the hippocampus may also be common in patients with mood disorders.

\section{Structural Brain Changes in Cushing's Disease or Exogenous Corticosteroid Exposure}

Several investigations have revealed structural brain changes in patients with Cushing's disease. An early investigation using pneumoencephalography, found cortical atrophy in $90 \%$ and cerebellar atrophy in $74 \%$ of subjects with Cushing's syndrome (Okuno et al. 1980). The degree of atrophy correlated with the severity of the illness and was present in all subjects who had mood symptoms. More recently, hippocampal volumes were determined with MRI in a group of 12 patients with Cushing's disease of 1-4 years duration (Starkman et al. 1992). In three patients, hippocampal volumes fell below the normal range (95\% confidence interval) reported in the literature. The degree of atrophy correlated with both the mean cortisol levels and the degree of declarative memory impairment. However, this study is weakened by the lack of a control group and its reliance on hippocampal volumes reported in the literature. Measurement of N-acetyl aspartate (NAA), a putative measure of neuronal integrity (Tsai and Coyle 1995), with ${ }^{1} \mathrm{H}$ magnetic resonance spectroscopy $\left({ }^{1} \mathrm{HMRS}\right)$ has also been used to examine CNS changes in Cushing's disease. Significant and widespread reductions in the NAA/creatine (CRE) ratio, which correlated with deficits in working memory, were observed in 22 patients with Cushing's syndrome secondary to pituitary or ectopic tumors compared to matched controls (D.L. Rosenstein, personal communication). Surgical excision of the tumors normalized cortisol levels, and was associated with improvement in NAA/CRE (6/7 patients) suggesting reversible volume reduction in this population.

Computed tomography (CT) studies in patients receiving prescription corticosteroids have also reported dose-dependent cerebral atrophy. After four weeks of adrenocorticotropin (ACTH) therapy, 11 of 15 (73\%) children with infantile spasms or Lennox syndrome had cerebral atrophy which reversed within four weeks of ending ACTH therapy (Okuno et al. 1980). Similarly, cerebral atrophy was reported on CT scans in 15 patients with autoimmune diseases receiving systemic corticosteroids for six months to five years (Bentson et al. 1978). The degree of atrophy correlated with the dose of corticosteroids and was reversed in two patients after dose reduction or discontinuation. No studies to date have used neuroimaging to specifically examine the hippocampus in patients receiving prescription corticosteroids.

\section{DISCUSSION}

This article has reviewed evidence that cumulative hippocampal changes by corticosteroids lead to abnormal neuroendocrine findings, cognitive impairment, and increased vulnerability to future episodes in people with mood disorders. Specifically, evidence in support of four predictions was examined.

First, frequency of DST non-suppression should increase with increasing number of affective episodes or more total time with mood symptoms. Two reports document such an increase (Yerevanian et al. 1984; Lenox et al. 1985). However, studies are needed to determine if persons with recurrent illness are more likely to have DST non-suppression even between episodes. If this is observed, then partially or completely irrevers- 
ible loss of normal feedback inhibition to the HPA axis, possible secondary hippocampal dysfunction, may have occurred.

Second, cognitive functions mediated by the hippocampus should worsen as the number of episodes or length of illness increases. This finding has been reported both in MDD and bipolar disorder (van Gorp 1998; Kessing 1998). One of these investigations found specific deficits in declarative memory consistent with hippocampal dysfunction in euthymic patients, suggesting that some degree of irreversible cognitive impairment may have occurred over time (van Gorp 1998).

Third, there should be a negative correlation between episode number or illness length and hippocampal volume. Two studies have reported such a correlation (Altshuler et al. 1991; Sheline et al. 1996). As with the worsening of cognition over time in people with mood disorders discussed above, decreased hippocampal volumes suggest cumulative and at least partially irreversible changes over multiple episodes. However, these data are from studies with small patient samples. In addition, these studies do not rule out the possibility that a preexisting small or dysfunctional hippocampus predisposes to DST non-suppression or greater number of affective episodes, and do not clearly link corticosteroids to hippocampal dysfunction. Reports of deficits in declarative memory and hippocampal atrophy in patients with Cushing's disease provide more direct evidence that these hormones lead to hippocampal changes in humans. Investigations of hippocampal volumes in patients receiving prescription corticosteroids might provide further support of this hypothesis.

Fourth, hypercortisolemic patients with mood disorders should have greater cognitive impairment and smaller hippocampal volumes than normocortisolemic patients. Several investigations support greater cognitive deficits in DST non-suppressors (Winokur et al. 1987; Wolkowitz et al. 1990; Siegel et al. 1989; Wauthy et al. 1991). Only depressed patients with normal cortisol levels have been examined with MRI of the hippocampus. Studies examining hippocampal size in depressed subjects with DST suppression versus non-suppression would be informative, as would studies in groups with high rates of non-suppression, such as psychotic depression and mixed mania. Controlled studies using neuroimaging and neurocognitive testing in these populations would help determine if corticosteroids are at least, in part, responsible for the hippocampal changes reported in MDD and bipolar disorder.

The nature of the hippocampal changes in humans is also important. Clearly, the rapid and reversible decline in declarative memory observed within a few days, or even hours, of corticosteroid exposure is not due to cell death. However, this may reflect changes in long term potentiation and neuronal excitability as has been sug- gested in animal models (Lupien and McEwen 1997). In addition, atrophy, when present, does not necessarily suggest neuronal death but could be secondary to reversible changes including the suppression of neurogenesis (Gould et al. 1998) or dendritic atrophy (Magariños et al. 1996; Popov and Bocharova 1992; Popov et al. 1992) reported in animals. Post mortem studies of hippocampal neuron number and morphology in persons with recurrent affective illness, Cushing's disease, and individuals who received chronic corticosteroid therapy are needed to better understand the nature of cellular changes in the human brain following chronic corticosteroid exposure. Newly emerging techniques, such as ${ }^{1}$ HMRS, may also permit a better understanding of cellular processes in the hippocampus in living humans by measuring relative concentrations of possible markers of neuronal viability such as NAA. Functional magnetic resonance imaging (fMRI) might allow examination of hippocampal function during memory testing in persons exposed to high levels of corticosteroids and normal controls.

The process of reversibility in humans is of much importance. Cognitive function appears to improve when mood improves (Sternberg and Jarvik 1976; Fromm and Schopflocher 1984; Bulbena and Berrios 1993; Henry et al. 1973; Richardson et al. 1994; Strömgren 1977), consistent with, at least, partially reversible changes in the hippocampus. However, the significant impairment in euthymic patients reported in some studies (van Gorp et al. 1998; Paradiso et al. 1997; Kessing 1998) is consistent with some degree of either irreversible or slow to resolve hippocampal changes. Perhaps, during a single or several mood episodes, a reversible insult to the hippocampus results in cognitive impairment as has been reported in animals with brief exposure to corticosteroids. Over time, with recurrent or chronic mood symptoms, permanent changes in the hippocampus may occur which could explain the cognitive changes observed even with euthymic mood. Thus, reversible hippocampal insults may eventually, with chronic or multiple episodes of affective illness, lead to permanent hippocampal dysfunction.

During stress paradigms in animals, levels of glutamate (Lowy et al. 1993) and serotonin (McKittrick and McEwen 1996) are increased in the hippocampus. Therefore, interventions designed to block or reverse the damaging effects of corticosteroids in the hippocampus in animal models have focused on: 1) reducing dose or corticosteroids; 2 ) use of serotonin reuptake enhancing agents; and 3) inhibition of excitatory amino acid release (McEwen 1997). Structural changes in the hippocampus associated with chronic stress in animals can be prevented by reducing corticosteroids levels through adrenalectomy. Similarly, reduction of corticosteroid levels with cyanoketone, a glucocorticoid synthesis inhibitor, prevented the dendritic atrophy associ- 
ated with 21 days of restraint in rats (Magariños et al. 1996). In humans, clinical trials of agents which inhibit cortisol synthesis (e.g., ketoconazole, metyrapone) and $\mathrm{CRH}$ or glucocorticoid receptor antagonists, could determine if lowering cortisol levels improves cognitive function on hippocampal atrophy.

Several reports in animals suggest that, tianeptine, which acts specifically to enhance serotonin reuptake, blocks and reverses the atrophy-inducing effects of corticosteroids. Tianeptine pretreatment prevents the impairment in spatial memory in rats observed during a chronic (21 day) stress model (Conrad et al. 1996). Tianeptine pretreatment also prevents reduction in branch points of CA3c pyramidal dendrites in the rat hippocampus following 21 day restraint stress or corticosterone therapy (Watanabe et al. 1992a). Daily tianeptine $(10 \mathrm{mg} / \mathrm{kg})$ in weeks 4 and 5 reverses 21-day corticosterone on restraint stress induced atrophy of apical dendritics of CA3 pyramidal neurons in rats (Magariños et al. 1999).

Tianeptine also reduces stress-related stimulation of the hypothalamic-pituitary-adrenal (HPA) axis in rats, thus reducing plasma ACTH and corticosterone (Delbende et al. 1991). However, reduction in HPA activity by tianeptine is not the primary reason for its blockade of hippocampal atrophy, because tianeptine both blocks (Watanabe et al.,1992a) and reverses (Magariños et al. 1999) the atrophy produced by exogenous glucocorticoid administration.

Hippocampal damage from corticosteroids can also be prevented in animals by pretreatment with phenytoin, which inhibits glutamate release and blocks glutamate actions by blocking sodium channels. Phenytoin $(40 \mathrm{mg} / \mathrm{kg})$ pretreatment prevents decreases in length and branch points in hippocampal dendrites associated with chronic restraint stress and daily corticosterone injections $(10 \mathrm{mg}$ ) in rats (Watanabe et al. 1992b). Stress-induced dentritic atrophy of CA3 pyramidal cells caused by chronic psychosocial stress in subordinate tree shrews is blocked by daily phenytoin administration (Magariños et al. 1996). Plasma levels of phenytoin achieved in the tree shrew $(20 \mu \mathrm{g} / \mathrm{ml})$ were similar to levels reported to be neuroprotective in other animal models and to those used in humans for seizure control. This finding suggests that currently available pharmacological interventions could be employed to prevent or reverse corticosteroid-induced hippocampal damage in humans.

\section{CONCLUSIONS}

Animal data indicate that corticosteroids are associated with cognitive impairment, cellular changes, and even neuronal death in the hippocampus. Cognitive deficits and reduced hippocampal volumes have been reported in patients with mood disorders. However, conclusive evidence linking these signs of hippocampal dysfunction with elevated corticosteroid levels are not yet available. If hippocampal changes in humans are secondary to corticosteroids, then research should focus on determining if this is due to reversible or irreversible processes. If irreversible, then the efficacy of early recognition and aggressive therapy of mood disorders with conventional therapies and potential prophylactic pharmacotherapeutic approaches including such agents as tianeptine, phenytoin and CRH antagonists must be examined. If the process is reversible even after recurrent affective episodes, then these same approaches should also be employed in people currently affected by chronic or recurrent mood symptoms.

\section{ACKNOWLEDGMENTS}

Research on the topic of this paper is supported by the National Alliance for Research on Schizophrenia and Depression (NARSAD), the Sarah M. and Charles E. Seay Center for Basic and Applied Research in Psychiatric Illness, John Schemerhorn Psychiatric Fund, the Theodore and Vada Stanley Foundation (ESB); the Health Foundation (New York), Servier (France), and NIH Grant MH 41256 (BSMc); and NIH Clinical Mental Health Services Transition Grant MH-53799 (AJR). The authors also thank Vicki Rankin for word processing, Nancy Thomas, M.A. and Susan Mahadi, M.Ed. for proofreading, and Kenneth Z. Altshuler, M.D., Stanton Sharp Distinguished Chair, Professor and Chairman, Department of Psychiatry, UT Southwestern Medical Center at Dallas for his administrative assistance.

\section{REFERENCES}

Abas MA, Sahakian BJ, Levy R (1990): Neuropsychological deficits and CT scan changes in elderly depressives. Psychol Med 20:507-520

Altshuler LL, Conrad A, Hauser PL, Li X, Guze BH, Denikoff K, Tourtellotte W, Post R (1991): Reduction of temporal lobe volume in bipolar disorder: A preliminary report of magnetic resonance imaging. [Letter]. Arch Gen Psychiatry 48:482-483

Altshuler LL, Bartzokis G, Grieder T, Curran J, Minta J (1998): Amygdala enlargement in bipolar disorder and hippocampal reduction in schizophrenia: An MRI study demonstrating neuroanatomic specificity. Arch Gen Psychiatry 55:663-664

Anath J, Gold J, Ghadirian AM, Engelsmann F (1981): Longterm effects of lithium carbonate on cognitive functions. J Psychiatric Eval Treatment 3:551-555

Arana GW, Mossman D (1988): The dexamethasone suppression test and depression. Endocrinol Metab Clin North Am 17(1):21-39

Arana GW, Baldessarini JR, Ornsteen M (1985): The dexamethasone suppression test for diagnosis and prognosis in psychiatry. Arch Gen Psychiatry 42:1193-1204 
Axelson DA, Doraiswamy PM, McDonald WM, Boyko OB, Tupler LA, Patterson LJ, Nemeroff CB, Ellinwood EH Jr, Krishman KR (1993): Hypercortisolemia and hippocampal changes in depression. Psychiatry Res 47:163-173

Baxendale S, Van Paesschen W, Thompson P, Duncan J, Harkness W, Shorvon S (1998): Hippocampal cell loss and gliosis: Relationship to preoperative and postoperative memory function. Neuropsychiatry Neuropsychol Behav Neurol 11:12-21

Bender BG, Lerner JA, Kollasch E (1988): Mood and memory changes in asthmatic children receiving corticosteroids. J Am Acad Child Adolesc Psychiatry 27(6):720-725

Bentson J, Reza M, Winter J, Wilson G (1978): Steroids and apparent cerebral atrophy on computed tomography scans. J Comput Assist Tomogr 2:16-23

Bohus B, Lissak K (1968): Adrenocortical hormones and avoidance behaviour in rats. Intern J Neuropharmacol 7:301-306

Bohus B (1970): Central nervous structures and the effect of ACTH and corticosteroids on avoidance behaviour: A study with intracerebral implantation of corticosteroids in the rat. Prog Brain Res 132:171-184

Bouille C, Bayle JD (1973): Effects of limbic stimulations or lesions on basal and stress-induced hypothalamic-pituitary-adrenocortical activity in the pigeon. Neuroendocrinology 13:264-277

Bulbena A, Berrios GE (1993): Cognitive function in the affective disorders: A prospective study. Psychopathology 26:6-12

Caine ED, Yerevanian BI, Bamford KA (1984): Cognitive function and the dexamethasone suppression test in depression. Am J Psychiatry 141:116-118

Calev A, Korin Y, Shapira B, Kugelmass S, Lerer B (1986): Verbal and non-verbal recall by depressed and euthymic affective patients. Psychol Med 16:789-794

Carroll BJ (1981): A specific laboratory test for the diagnosis of melancholia: Standardization, validation, and clinical utility. J Clin Endocrinol Metab 51:433-437

Christodoulou GN, Kokkevi A, Lykouras EP, Stafanis CN, Papadimitriou GN (1981): Effects of lithium on memory. Am J Psychiatry 138:847-848

Coffman JA, Bornstein RA, Olson SC, Schwarzkopf SB, Nasrallah HA (1990): Cognitive impairment and cerebral structure by MRI in bipolar disorder. Biol Psychiatry 27:1188-1196

Coello E, Ardila A, Rosselli M (1990): Is there a cognitive marker in major depression? Intern J Neuroscience 50:137-145

Conrad CD, Galea LAM, Kuroda Y, McEwen BS (1996): Chronic stress impairs rat spatial memory on the $Y$ maze, and this effect is blocked by tianeptine pretreatment. Behav Neurosci 110:1321-1334

Delbende C, Contesse V, Mocaer E, Kamoun A, Vaudry H (1991): The novel antidepressant, tianeptine, reduces stress-evoked stimulation of the hypothalamo-pituitaryadrenal axis. Eur J Pharmacol 202:391-396

De Kloet, Vrevgdenhil E, Oitzl M, Joëls M (1998): Brain corticosteroid receptor balance in health and disease. Endocr Rev 19(3):269-301

Drevets WC, Price JL, Simpson JR, Todd RD (1997): Subgen- ual prefrontal cortex abnormalities in mood disorders. Nature 386:824-827

Duman RS, Heninger GR, Nestler EJ (1997): A molecular and cellular theory of depression. Arch Gen Psychiatry 54:597-606

Dunn JD, Orr SE (1984): Differential plasma corticosterone responses to hippocampal stimulation. Brain Res 54(1):1-6

Eichenbaum H, Otto T, Cohen NJ (1992): The hippocampus-what does it do? Behav Neural Biol 57:2-36

Engelsmann F, Ghadirian AM, Grof P (1992): Lithium treatment and memory: A long-term follow-up study. J Clin Psychopharmacol 8:207-211

Feldman S , Conforti N (1976): Feedback effects of dexamethasone on adrenocortical responses in rats with fornix section. Hormone Res 7:56-60

Feldman S , Conforti N (1980): Participation of the dorsal hippocampus in the glucocorticoid feedback effect on adrenocortical activity. Neuroendocrinology 30:52-55

Feldman S, Weidenfeld J (1991): Depletion of hypothalamic norepinepherin and serotonin enhances the dexamethasone negative feedback effect on adrenocortical secretion. Psychoneuroendocrinology 16(5):397-405

Fischette CT, Komisaruk BR, Edinger HM, Feder HH, Siegel A (1980): Differential fornix ablations and the circadian rhythmicity of adrenal corticosteroid secretion. Brain Res 195:373-387

Friedman MJ, Culver CM, Ferrell RB (1977): On the safety of long-term treatment of lithium. Am J Psychiatry 230:1123-1126

Fromm D, Schopflocher D (1984): Neuropsychological test performance in depressed patients before and after drug therapy. Biol Psychiatry 19:55-72

Georgotas A, McCue RE, Kim M, Hapworth WE, Reisberg B, Stoll PM, Sinaiko E, Fanelli C, Stokes PE (1986): Dexamethasone suppression in dementia, depression, and normal aging. Am J Psychiatry 143(4):452-456

Golomb J, Kluger A, deLeon MJ, Ferris SH, Covit A, Mittelman MS, Cohen J, Rusinek H, DeSanti S, George AE (1994): Hippocampal formation size in normal human aging: A correlate of delayed secondary memory performance. Learning Mem 1:45-54

Gould E, Tanapat P, McEwen BS, Flugge G, Fuchs E (1998): Proliferation of granule cell precursors in the dentate gyrus of adult monkeys is diminished by stress. Proceedings of the National Academy of Sciences, USA, 95(6):3168-3171

Greden JF, Gardner R, King D, Grunhaus L, Caroll B, Kvonfol Z (1983): Dexamethasone suppression tests in antidepressant treatment of melancholia. Arch Gen Psychiatry 40:493-500

Greidanus TJB (1970): Effects of steroids on extinction of an avoidance response in rats. A structure-activity relationship study. Prog Brain Res 32:185-191

Henry GM, Weingartner H, Murphy DL (1973): Influence of affective states and psychoactive drugs on verbal learning and memory. Am J Psychiatry 130:966-971

Herman JP, Cullinan, WE (1997): Neurocircuitry of stress: Central control of the hypothalamo-pituitary-adrenocortical axis. Neuroscience 20(2):78-84 
Holsboer F, vonBardeleben U, Wiedemann K, Muller A Stalla GK (1987): Serial assessment of corticotropinreleasing hormone response after dexamethasone in depression implications for pathophysiology of DST nonsuppression. Biol Psychiatry 22:228-234

Holsboer-Trachsler E (1991): Repeated administration of the combined Dexamethasone human corticotropin releasing hormone stimulation test during treatment of depression. Psychiatry Res 38:163-171

Holsboer-Trachsler E, Hemmeter U, Hatzinger M, Seifritz E, Gerhard U, Hobi V (1994): Sleep deprivation and bright light as potential augmenters of antidepressant drug treatment-neurobiological and psychometric assessment of course. J Psychiat Res 28(4):381-399

Jacobson L, Sapolsky R (1991): The role of the hippocampus in feedback regulation of the hypothalamic-pituitaryadrenocortical axis. Endocr News 12:118-134

Joffe RT, MacDonald C, Kutcher SP (1988): Lack of differential cognitive effects of lithium and carbamazepine in bipolar affective disorder. J Clin Psychopharmacol $8: 425-428$

Kandel ER, Schwartz JH (1985): Principles of Neural Science. New York, NY, Elsevier, p 810

Keenan PA, Jacobson MW, Soleymani RM, Mayes MD, Stress ME, Yaldoo DT (1996): The effect on memory of chronic prednisone treatment in patients with systemic disease. Neurology 47:1396-1402

Kessing LV (1998): Cognitive impairment in the euthymic phase of affective disorder. Psychol Med 28:1027-1038

Kim C, Kim CU (1961): Effect of partial hippocampal resection on stress mechanism in rats. Am J Physiol 201(2):337-340

Knigge KM, Hays M (1963): Evidence of inhibitive role of hippocampus in neural regulation of ACHT release. Proc Soc Exp Biol Med 114:67-69

Kocsis JH, Shaw ED, Stokes PE, Wilner P,Elliot AS, Sikes C, Myers B, Manevitz A, Parides M (1993): Neuropsychologic effects of lithium discontinuation. J Clin Psychopharmacol 13:268-275

Lenox RH, Teyser JM, Rothschild B, Shipley J, Weaver L (1985): Failure to normalize the dexamethasone suppression test: association with length of illness. Biol Psychiatry 20:329-352

Liberzon I, Krstov M, Young EA (1997): Stress-restress: Effects on ACTH and fast feedback. Psychoneuroendocrinology 22:443-453

Lowy MT, Gault L, Yamamoto BK (1993): Adrenalectomy attenuates stress-induced elevations in extracellular glutamate concentrations in the hippocampus. J Neurochem 61:1957-1960

Lund Y, Nissen M, Rafaelson O (1982): Long-term lithium treatment and psychological functions. Acta Psychiatry Scand 65:233-244

Lupien SJ, McEwen BS (1997): The acute effects of corticosteroids on cognition: integration of animal and human model studies. Brain Res Rev 24:1-27

Magariños AM, McEwen BS, Flugge G, Fuchs E (1996): Chronic psychosocial stress causes apical dendritic atrophy of hippocampal CA3 pyramidal neurons in subordinate tree shrews. J Neurosci 16:3534-3540
Magariños A, Deslandes A, McEwen BS (1999): Effects of antidepressants and benzodiazepam treatments on the dendritic structure of CA3 pyramidal neurons after chronic stress. Eur J Pharmacol 371:113-122

Mandell AJ, Chapman LF, Rand RW, Walter RD (1962): Plasma corticosteroids: Changes in concentration after stimulation of hippocampus and amygdala. Science 139:1212

Marcos T, Salamero M, Gutierrez F, Catalan R, Gasto C, Lazaro L (1994): Cognitive dysfunction in recovered melancholic patients. J Affective Disord 31:133-137

Marusarez TZ, Wolpert EA, Koh SD (1981): Memory processing with lithium carbonate. J Clin Psychiatry 42:190-192

Mauri M, Sinforiani E, Bono G, Vignati F, Berselli ME, Attanasio R, Nappi G (1993): Memory impairment in Cushing's disease. Acta Neurol Scand 87:52-55

McCormick CM, McNamara M, Mukhopadhyay S, Kelsey JE (1997): Acute corticosterone replacement reinstates performance on spatial and nonspatial memory tasks 3 months after adrenalectomy despite degeneration in the dentate gyrus. Behav Neurosci 111(3):518-531

McEwen BS, Weiss J, Schwartz L (1968): Selective retention of corticosterone by limbic structures in rat brain. Nature 220:911-912

McEwen BS (1997): Possible mechanisms for atrophy of the human hippocampus. Mol Psychiatry 2:255-262

McEwen BS (1999): Stress and the aging hippocampus. Frontiers Neuroendocrinol, 20:49-70

McKay AP, Tarbuck AF, Shapleske J, McKenna PJ (1995): Neuropsychological function in manic-depressive psychosis evidence for persistent deficits. British J Psychiatry 167:51-57

McKittrick CR, McEwen BS (1996): Regulation of seritonergic function in the CNS by steroid hormones and stress. In Stone TW (ed), CNS Neurotransmitters and Neuromodulators: Neuroactive Steroids. Boca Raton, FL, CRC Press, pp 37-76

Moberg GP, Scapagnini U, deGroot J, Ganong WF (1971): Effect of sectioning the fornix on diurnal fluctuation in plasma corticosterone levels in the rat. Neuroendocrinology 7:11-15

Morice R (1990): Cognitive inflexibility and pre-frontal dysfunction in schizophrenia and mania. Brit J Psychiatry 157:50-54

Naber D, Sand P, Heigl B (1996): Psychopathological and neuropsychological effects of 8-days' corticosteroid treatment: A prospective study. Psychoneuroendocrinology 21:25-31

Newcomer JW, Craft S, Hershey T, Askins K, Bardgett ME (1994): Glucocorti-coid-induced impairment in declarative memory performance in adult humans. J Neurosci 14:2047-2053

Newcomer JW, Selke G, Melson AJ, Gross J, Richards K, Hershey T, Craft S, Alderson A, Gottlieb L (1997): Dose- and time-dependent cortisol-induced decrease in memory performance in humans. Soc Neurosci Abstr 23(2):2121

Okuno T, Ito M, Konishi Y, Yoshioka M, Nakano Y (1980): Cerebral atrophy following ACTH therapy. J Comput Assist Tomogr 4:20-23 
Oliveri RL, Sibilia G, Valentino P, Russo C, Romeo N, Quattrone A (1998): Pulsed methylprednisolone induces a reversible impairment of memory in patients with relapsing-remitting multiple sclerosis. Acta Neurol Scand 97:366-369

Ongür D, Drevets WC, Price JL (1998): Glial reduction in the subgenual prefrontal cortex in mood disorders. Proc Natl Acad Sci USA 95:13290-13295

Paradiso S, Lamberty GJ, Garvey MJ, Robinson RG (1997): Cognitive impairment in the euthymic phase of chronic unipolar depression. J Nervous Mental Dis 185(8):748754

Popov VI, Bocharova LS, Bragin AG (1992): Repeated changes of dendritic morphology in the hippocampus of ground squirrels in the course of hibernation. Neuroscience 48:45-51

Reuss VI, Targum SD, Weingardner H, Post RM (1979): Effect of lithium carbonate on memory processes of bipolar affectively ill patients. Psychopharmacology 63:39-42

Richardson JS, Keegan DL, Bowen RC, Blackshaw SL, Cebrian-Perez S, Dayal N, Saleh S, Skrikhande S (1994): Verbal learning by major depressive disorder patients during treatment with fluoxetine or amitriptyline. Int Clin Psychopharmacol 9:35-40

Roy-Byrne, PP, Weingartner H, Bierer LM, Thompson K, Post RM (1986): Effortful and automatic cognitive processes in depression. Arch Gen Psychiatry 43:265-267

Rubin RT, Mandell AJ, Crandall PH (1966): Corticosteroid responses to limbic stimulation in man: Localization of stimulus sites. Science 153:767-768

Rubinow DR, Post RM, Savard R, Gold PW (1984): Cortisol hypersecretion and cognitive impairment in depression. Arch Gen Psychiatry 41:279-283

Sabe L (1995): Dissociation between declarative and procedural learning in dementia and depression. J Clin Exp Neuropsychol 17(6):841-848

Sachar E (1971): Cortisol production in depressive illness: A clinical and biochemical clarification. Arch Gen Psychiatry 23(4):289-298

Sapin LR, Berrettini WH, Nurnberger JI, Rothblat LA (1987): Mediational factors underlying cognitive changes and laterality in affective illness. Biol Psychiatry 22:979-986

Sapolsky R, Krey L, McEwen BS (1986a): The adrenocortical axis in the aged rat: Impaired sensitivity to both fast and delayed feedback inhibition. Neurobiol Aging 7:331-335

Sapolsky RM, Krey LC, McEwen BS (1986b): The neuroendocrinology of stress and aging: The glucocorticoid cascade hypothesis. Endocr Rev 7:284-301

Sapolsky R (1992): Stress, the Aging Brain and the Mechanisms of Neuron Death. Cambridge, MIT Press

Schmider J, Lammens C, Grotthardt V, Dettling M, Holsboer F, Heuser I (1995): Combined dexamethasone/corticotropin-releasing hormone test in acute and remitted manic patients in acute depression, and in normal controls. I. Biol Psychiatry 38:797-802

Scoville W, Milner B (1957): Loss of recent memory after bilateral hippocampal lesions. J Neurol Neurosurg Psychiatry 20:11-21

Shah PJ, Ebmeier KP, Glabus MF, Goodwin GM (1998): Cortical grey matter reductions associated with treatment- resistant chronic unipolar depression. Br J Psychiatry 172:527-532

Sheline YI, Wang PW, Gado MN, Csernansky JC, Vannier MW (1996): Hippocampal atrophy in recurrent major depression. Proc Natl Acad Sci USA 93:3908-3913

Sheline YI, Gado Mokhtar H, Price JL (1998): Amygdala core nuclei volumes are decreased in recurrent major depression. Neuroscience 9(9):2023-2028

Shulkin J, Gold PW, McEwen BS (1998): Induction of corticotropin-releasing hormone gene expression by glucocorticoids: Implication for understanding the states of fear and anxiety and allostatic load. Phychoneuroendocrinology 23(3):219-243

Siegel B, Gurevich D, Oxenkrug GF (1989): Cognitive impairment and cortical resistance to dexamethasone suppression in elderly depression. Biol Psychiatry 25:229-234

Slusher MA, Hyde JE (1961): Effect of limbic stimulation on release of corticosteroids into the adrenal venous effluent of the cat. Endocrinol 69:1080-1084

Slusher MA (1966): Effects of cortisol implants in the brainstem and ventral hippocampus on diurnal corticosteroid levels. Exp Brain Res 1:184-194

Squire LR, Judd LL, Janoswky DS, Huey LY (1980): Effects of lithium carbonate on memory and other cognitive functions. Am J Psychiatry 137:1042-1046

Squire LR (1992): Memory and the hippocampus: A synthesis from findings with rats, monkeys, and humans. Psychol Rev 99:195-231

Starkman MN, Schteingart DE (1981): Neuropsychiatric manifestations of patients with Cushing's syndrome. Arch Intern Med 141:215-219

Starkman MN, Gebarski SS, Berent S, Schteingart DE (1992): Hippocampal formation volume, memory dysfunction, and cortisol levels in patients with Cushing's syndrome. Biol Psychiatry 32:756-765

Sternberg DE, Jarvik ME (1976): Memory function in depression. Arch Gen Psychiatry 33:219-224

Strömgren LS (1977): The influence of depression on memory. Acta Psychiatry Scand 56:109

Targum SD (1984): Persistent neuroendocrine dysregulation in major depressive disorder: A marker for early relapse. Biol Psychiatry 19(3):305-318

Telford R, Worrall EP (1978): Cognitive functions in manicdepressives: effects of lithium and phostigmine. $\mathrm{Br} \mathrm{J}$ Psychiatry 133:424-428

Tham A, Engelbrektson K, Mathe AA, Johnson L, Olsson E, Aberg-Wistedt A (1997): Impaired neuropsychological performance in euthymic patients with recurring mood disorders. J Clin Psychiatry 58(1):26-29

Trichard C, Martinot JL, Alagille M, Masure MC, Hardy P, Ginestet D, Feline A (1995): Time course of prefrontal lobe dysfunction in severely depressed in-patients: a longitudinal neuropsychological study. Psychol Med 25:79-85

Tsai G, Coyle JT (1995): N-acetylasparate in neuropsychiatric disorders. Prog Neurobiol 46:531-540

van Gorp WG (1998): Cognitive impairment in euthymic bipolar patients with and without prior alcohol dependence. A preliminary study. Arch Gen Psychiatry 55(1):41-46 
Vicedomini JP, Nonneman AJ, DeKosky ST, Scheff SW (1986): Perinatal glucocorticoids disrupt learning: A sexually dimorphic response. Physiol Behav 36:145-149

Watanabe Y, Gould E, Daniels DC, Cameron H, McEwen BS (1992a): Tianeptine attenuates stress-induced morphological changes in the hippocampus. Eur J Pharmacol 222:157-162

Watanabe Y, Gould E, Cameron HA, Daniels DC, McEwen BS (1992b): Phenytoin prevents stress- and corticosterone-induced atrophy of CA3 pyramidal neurons. Hippocampus 2(4):431-435

Wauthy J, Ansseau M, vonFrenckell RM, Mormont C, Legros, JJ (1991): Memory disturbances and dexamethasone suppression test in major depression. Biol Psychiatry 30:736-738

Weingartner H, Cohen RM, Murphy DL, Martello J, Gerdt C (1981): Cognitive processes in depression. Arch Gen Psychiatry 38:42-47
Wilson MM, Greer SE, Greer MA, Roberts L (1980): Hippocampal inhibition of pituitary-adrenocortical function in female rats. Brain Res 197:433-441

Winokur G, Black DW, Nasrallah A (1987): DST Nonsuppressor status: relationship to specific aspects of the depressive syndrome. Biol Psychiatry 22:360-368

Wolkowitz OM, Reus VI, Weingartner H, Thompson K, Breier A, Doran A, Rubinow D, Pickar D (1990): Cognitive effects of corticosteroids. Am J Psychiatry 147:12971303

Yerevanian BI, Privitiera MR, Milanese E, Sagi, EA, Russotto JC (1984): The dexamethasone suppression test during recurrent major depressive episodes. Biol Psychiatry 19(3):407-412

Young EA, Haskett RF, Murphy-Weinberg V, Watson SJ, Akil H (1991): Loss of glucocorticoid fast feedback in depression. Arch Gen Psychiatry 48:693-699 